\title{
Preserving farm freshness: Consumer preferences for local value-added products at urban farmers markets
}

\author{
Virginia Quick ${ }^{a *}$ \\ Rutgers University \\ Lauren B. Errickson ${ }^{b}$ \\ Rutgers Cooperative Extension, Rutgers \\ University
Graham E. Bastian, ${ }^{\mathrm{c}}$ Grace Chang, ${ }^{\mathrm{d}}$ Sarah Davis ${ }^{\mathrm{e}}$
Rutgers University

Anthony Capece ${ }^{\mathrm{f}}$

Elijah’s Promise

Ethan D. Schoolman ${ }^{g}$

Submitted January 27, 2021 / Revised May 4 and August 13, 2021 / Accepted August 16, 2021 /

Published online February 2, 2021

Citation: Quick, V., Errickson, L. B., Bastian, G. E., Chang, G., Davis, S., Capece, A., \& Schoolman, E. D. (2022).
Preserving farm freshness: Consumer preferences for local value-added products at urban farmers markets. Journal
of Agriculture, Food Systems, and Community Development, 11(2), 113-134. https://doi.org/10.5304/jafscd.2022.112.004

Copyright (C) 2022 by the Authors. Published by the Lyson Center for Civic Agriculture and Food Systems. Open access under CC-BY license

\begin{abstract}
Farmers markets (FMs) are known for fresh fruits and vegetables, but many also feature shelf-stable,

a * Corresponding author: Virginia Quick, PhD, RDN, Director of the Didactic Program in Dietetics, Department of Nutritional Sciences, Rutgers University; 26 Nichol Avenue, Davison Hall; New Brunswick, NJ 08901 USA; +1-848-9320950; vquick@,njaes.rutgers.edu

b Lauren B. Errickson, MS, Senior Program Administrator, Rutgers Cooperative Extension, Rutgers University; lauren.errickson@,rutgers.edu

c Graham E. Bastian, RDN, Doctoral Candidate, Department of Nutritional Sciences, Rutgers University; g.e.bastian@rutgers.edu

d Grace Chang, BS, Research Assistant, Rutgers University; gracehanel@gmail.com

e Sarah Davis, BS, Research Assistant, Rutgers University; sld197@scarletmail.rutgers.edu

f Anthony Capece, Associate Director, Elijah's Promise, New Brunswick, NJ, USA; anthony.capece@elijahspromise.org

g Ethan D. Schoolman, PhD, Assistant Professor, Department of Human Ecology, Rutgers University; es808@sebs.rutgers.edu
\end{abstract}

value-added products (VAPs) like sauces, jams, and fermented produce. Despite the potential importance of locally sourced VAPs to FMs, farmers, and food-insecure communities, few if any studies have examined consumer preferences related to small-batch VAPs of the kind often prepared for sale at FMs. To address this gap in knowledge, this study presents the results of a collaboration between farmers, researchers, and a not-for-profit community kitchen in New Jersey. First, using the Food Choice Process Model as a framework, we

\section{Author Contributions}

All authors carried out the research study, collected data, and participated in the draft of the manuscript. EDS, AC, LBE, and VQ conceived the study and participated in its design and coordination. SD transcribed verbatim the digitally recorded focus groups. GC and VQ conducted the analyses for the sensory food evaluation tests. VQ, LBE, and GEB were involved in the qualitative analysis of the transcribed scripts. All authors have read and approved the final manuscript.

\section{Funding Disclosure}

This work was supported by the USDA Agricultural Marketing Service (CFDA \#10.172, Local Food Promotion Program). 
conducted focus groups (four focus groups: 6-10 participants per group; 33 participants total) to gain insight into what would make locally sourced VAPs appealing to residents of food-insecure areas. Major themes that emerged were cost, quality, and health; less common themes included culture, food safety, and ethical values. Second, drawing on focus group data, we developed new VAPsincluding tomato sauce, applesauce, hot pepper relish and pickled jalapeños-using ingredients from local farms. Third, we conducted controlled sensory evaluations to assess FM customer satisfaction with project-specific VAPs. Urban consumers $(N=49)$ ranked a store-bought tomato sauce significantly higher on taste, sweetness, saltiness, and thickness, compared to the VAP version. However, VAP and store-bought applesauces were comparable across most attributes, and reactions to the hot pepper relish and pickled jalapeños were broadly positive. Overall, findings suggest that locally sourced VAPs tailored to the preferences of particular markets may constitute a valuable addition to the local food landscape in food-insecure areas.

\section{Keywords}

Farmers Market, Value-Added Product, Local Food, Food Security, Food Choice, Urban Consumers

\section{Introduction}

Local food systems, understood as networks of food supply chains structured to minimize physical and relational distance between farmers who grow food and people who eat it (Dansero \& Puttilli, 2014; Schoolman, 2020), have experienced dramatic growth over the past 20 years. Once a niche market for counterculture consumers, local food has become, since the early 1990s, a US $\$ 8.7$ billion market involving 169,000 farms (U.S. Department of Agriculture, National Agricultural Statistics Service [USDA NASS], 2016a). Farmers markets (FMs), defined as "a public and reoccurring assembly of farmers or their representatives selling the food that they produced directly to consumers" (Farmers Market Coalition, 2016), are perhaps the most recognizable kind of direct marketing channel for connecting consumers with nearby farmers.
Surging interest in local food can clearly be seen in how FMs have multiplied. According to the USDA Agricultural Marketing Service, in 1994 there were 1,755 FMs in the U.S.; in 2019, there were 8,771 (Tropp, 2019), with over $\$ 711$ million in direct market sales (USDA NASS, 2016b).

Farmers markets have the potential to provide a wide range of social and economic benefits to consumers, farmers, and communities. Regarding consumers in general, several studies have found that access to local food through FMs and community supported agriculture (CSA) is associated with positive health outcomes such as reductions in childhood obesity and lower adult body mass index (Berning, 2012; Bimbo et al., 2015; Rundle et al., 2009). Farmers markets are particularly important for low-income communities in urban areas where access to grocery stores is limited and food insecurity is high (Evans et al., 2015; McGill, 2015; Ruelas et al., 2012; Spalding et al., 2012). Controlled intervention experiments have shown that introducing FMs can increase fruit and vegetable consumption among key clienteles, including women using family planning clinics, expectant mothers, and WIC recipients (Ball et al., 2018; Evans et al., 2012; Grin et al., 2013; Pitts et al., 2013; but see Olsho et al., 2015; Pellegrino et al., 2018). Indeed, motivated by the capacity of FMs to help address inequalities in healthy food access, a growing number of states prioritize making FMs and participating farmers eligible to accept payments via SNAP, WIC, and other food assistance programs (Briggs et al., 2010).

The community health implications of successful FMs are synergistic with other public goods. Beyond meeting the needs of individual consumers, FMs serve as highly social public spaces, enlivening communities and bringing shoppers to downtown areas (Darnton, 2012; Farmer et al., 2011; Johnson, 2013; Silkes, 2012) while potentially boosting property values (Collins, 2020). Farmers and small food businesses directly benefit from FMs by building a loyal, local customer base, retaining the full sale price of their products, and learning first-hand where consumer demand is going unmet (Gerbasi, 2006; Gillespie et al., 2007; Hinrichs et al., 2004). More broadly, by bringing farmers, food entrepreneurs, "locavores," and 
miscellaneous actors in the local food economy physically together, FMs create fertile ground for social learning and facilitate new collaborations in business and civil society around the idea of local food (Beckie et al., 2012; Gillespie et al., 2007; Wittman et al., 2012).

Farmers markets have thrived over the past twenty years, and researchers have documented their benefits to consumers and communities, particularly for economically vulnerable groups (Ball et al., 2018; Gillespie et al., 2007). It is for precisely this reason that recent challenges to FMs present an urgent concern. Growth in FMs has been dramatic when viewed over a timespan measured in decades. But this growth has essentially plateaued since 2016, while total sales through direct-toconsumer markets have also stagnated or declined (McKee, 2021; Printezis \& Grebitus, 2018). Supermarkets, wholesale clubs, and most recently mealkit delivery services increasingly highlight when products are sourced from farms that share a state or region with consumers (Bloom \& Hinrichs, 2017; McKee, 2021). Efforts by large, conventional stores to establish local sourcing bona fides may appeal especially to consumers whose idea of what constitutes "local" food is relatively flexible, and who find FMs too inconvenient to be a primary shopping destination (Dunne et al., 2011; McKee, 2021). Even intermediated short food supply chains may be siphoning customers away from FMs and CSA (Printezis \& Grebitus, 2018). Moreover, economic challenges for FMs and participating farmers were evident even before the COVID19 pandemic (Helmer, 2019). In the wake of the nationwide economic crisis of 2020 and 2021, early evidence paints a grim picture of closures and steep losses for FMs and other channels for locally sourced food (O'Hara et al., 2021; Thilmany et al., 2020).

Given the clear relevance of successful FMs to public health, community wellbeing, and small farmer livelihoods, it is important that FMs find ways to continue to thrive in a competitive environment for the attention of local food shoppers. This will be especially true once the economic suffocation of the pandemic has subsided. Direct farmer participation in the production and marketing of value-added products (VAPs) may make an important contribution to efforts to stabilize FMs and strengthen business for participating farmers, according to reports from agricultural organizations and cooperative extension (Berry, 2019; Born \& Bachman, 2006; Brzozowski, 2019). Historically, the concept of farmers "adding value" to raw farm products has mainly described when "farmers participate in stages beyond production in the agricultural supply chain, such as product transformation, distribution, [and] storage ... and transform their roles from raw commodity producers to agribusiness owners with extended capabilities" (Lu \& Dudensing, 2015, p. 3). "Traditional” value-adding in this sense includes both on-farm processing of crops into products like sauces and jams, and also when farmers outsource the actual "transformation" of crops-e.g., cooking, pickling, fermenting-but still retain a role in the distribution of the finished product (Born, 2001; Born \& Bachman, 2006; Sayre, 2006). More recently, adding value has also been used, in an "emerging" sense, to describe differentiations made in how crops are grown and marketed; for instance, by applying designations related to sustainability, labor practices, or shared commitments to place (Clark et al., 2020; Lu \& Dudensing, 2015, p. 3).

In this study, we are interested in what $\mathrm{Lu}$ and Dudensing (2015) call "traditional" value-added agriculture because of the potential for increased marketing of VAPs by farmer-vendors at FMs to make progress toward several economic and social goals at once. First and foremost, VAPs have the potential to help FMs and participating farmers by increasing sales (e.g., Born \& Bachman, 2006). In a recent review of the literature on FMs, "lack of food variety" was the most frequently cited "service delivery barrier" to FMs attracting more customers (Freedman et al., 2016, p. 1148). Robust offerings of VAPs like sauces and condiments could prove important for consumers for whom lack of food variety, and the inability to do "onestop shopping," constitutes a significant impediment to regularly patronizing FMs. VAPs also enable farmers to reduce waste by processing surplus produce—including imperfect "seconds"-for consumption, rather than selling at cost or at a loss to wholesalers. Moreover, FMs with a robust selection of VAPs have more to offer customers during 
cold-weather months; popular "winter markets," in turn, extend the economic usefulness of FMs for farmers (Sparks, 2012).

Crucially, increased offerings of VAPs at FMs also stand to benefit consumers and communities. For a number of reasons, this is arguably nowhere more true than in low-income urban areas where, as noted above, FMs already constitute an important source of fresh, healthy food. First, FMs may be able to attract more farmers and stay open for more days and longer hours, if participating farmers are able to earn income not just from fresh produce but also from VAPs. Extra days and hours to shop at FMs, in turn, would create more opportunities for consumers to buy fresh fruits and vegetables, with proven positive impacts on health. Indeed, at winter markets where VAPs may constitute a significant source of income for vendors, farmers can offer greenhouse-grown produce and hardy winter crops to low-income consumers, including those purchasing with WIC and SNAP benefits (Downs, 2016). Second, for people who face significant constraints on time and economic resources (Giurge et al., 2020; LeDoux \& Vojnovic, 2013), the ability to minimize time spent shopping represents a powerful incentive to patronize full-service grocery stores. FMs that offer a relatively competitive selection of VAPs may thus make it possible for low-income consumers in particular to take more frequent advantage of the fresh fruits and vegetables for which FMs are best known. Third, locally sourced VAPs, when made with minimal processing and fewer added sugars, may present a healthier alternative to highly processed, brand-name products available at conventional grocery stores (McManus, 2020; Neri et al., 2019). Finally, as we note above, FMs can deliver tangible benefits to entire communities, serving as downtown anchors and visible signs of economic revival and civic spirit. To the extent that VAPs allow FMs to draw more customers and stay open for more of the year, the possibility of significant, positive impacts for neighboring businesses and the social economy should not be overlooked (Beckie et al., 2012; Darnton, 2012; Wittman et al., 2012).

Few if any studies have examined consumer expectations and preferences related to small-batch
VAPs prepared by farmers or small food businesses for sale at FMs, despite their potential importance to farmers, consumers, and communities (Govindasamy et al., 2002). Moreover, because the heath impacts of FMs are likely greatest in areas where existing access to healthy food is lowest, the need for research into consumers and FM VAPs is especially pressing where FMs in low-income, food-insecure areas are concerned. It is this gap in the literature that we aim to address with this study. Specifically, we present the results of a collaboration between farmers, researchers, and a not-forprofit community kitchen to develop and market VAPs for FMs in the city of New Brunswick, New Jersey. Drawing on existing models that situate food choices in the context of "personal food systems" (Connors et al., 2001; Furst et al., 1996), we conducted focus groups with New Brunswick-area consumers to gain insight into what would make locally sourced VAPs appealing to residents of food-insecure areas. In collaboration with farmers and chefs at a local community kitchen, we developed new VAPs to meet the needs and preferences of this particular population. We then conducted controlled sensory evaluations to assess FM customer satisfaction with VAPs made using ingredients from local farms. The results of this mixedmethods study offer insight into what residents of a city with high rates of food insecurity are looking for in locally sourced VAPs. More generally, this project demonstrates the usefulness and feasibility of basic, inexpensive market research for farmers and community organizations interested in bringing new VAPs to urban farmers markets.

\section{Materials and Methods}

This study was conducted by researchers at Rutgers University and staff at Elijah's Promise (EP), a New Brunswick, New Jersey-based not-for-profit food aid and empowerment organization whose motto is "Food Changes Lives." In addition to a community soup kitchen that serves over 100,000 meals a year to food-insecure individuals, EP runs the Promise Culinary School and provides numerous social services to New Brunswick residents. This multidisciplinary and mixed-methods study was approved by the Institutional Review Board at Rutgers University. 


\section{Community Focus Groups}

To understand which aspects of locally sourced VAPs might be of interest to primarily low-income, urban area consumers, we conducted a series of focus groups with New Brunswick residents. A focus group can be thought of as a "group interview" where a moderator presents questions or prompts to a small number of participants, who then engage in guided discussion (Oates, 2000). As with in-depth interviews with one subject, focus groups give participants significant agency in what is talked about, within the bounds of the motivating research questions. Focus groups can be especially useful for gaining insight into underrepresented or marginalized social groups because sampling is purposive and people who share core values and experiences can add to, expand on, and ask questions about one another's stories (Kevern \& Webb, 2001; Kagawa-Singer et al., 2009). Focus groups are also ideal for research on food consumption practices, because feelings and thoughts on shopping and food are generally relatively amenable to being shared in a group setting (e.g., Jefrydin et al., 2019; Tiedje et al., 2014; Zepeda et al., 2006). When the topic of discussion is largely non-sensitive in nature, focus groups allow researchers to gather rich, qualitative data from more people in a shorter period of time, relative to in-depth interviews. Further, conversation generated among participants in a group setting may spur valuable input beyond what would be shared in an individual interview.

\section{Sampling and subject recruitment}

The city of New Brunswick is located in central New Jersey, about 40 miles southwest of New York City. During the study period (2019), 46.8\% of New Brunswick's 55,960 residents identified as Hispanic or Latino, $26.7 \%$ identified as White alone, $15.3 \%$ as Black or African-American alone, and $9.7 \%$ as Asian alone (U.S. Census Bureau, 2019a); the median household income was $\$ 43,783$; and $34.4 \%$ of residents were below the federal poverty line (U.S. Census Bureau, 2019b). New Brunswick thus has significantly more non-White and low-income persons than New Jersey as a whole (U.S. Census Bureau, 2019c). The Hispanic/Latino population of New Brunswick is diverse, and has grown significantly in recent decades (Listokin et al., 2016). In 2019, immigrants and descendants of immigrants from Mexico made up the largest percentage $(42.3 \%$, down from $50.1 \%$ in 2016$)$ of people who identified as Hispanic or Latino. The next largest Hispanic/Latino group consisted of people who trace their origin to the Dominican Republic (15.5\% in 2016, and likely greater in 2019), followed by Central American countries, then Puerto Rico (Sandoval, n.d.; U.S. Census Bureau, 2019a). According to a 2016 survey of New Brunswick residents who were born outside the U.S., $27 \%$ were born in the Dominican Republic, 23\% were born in Mexico, and 13\% were born in El Salvador, Guatemala, or Honduras (Koning et al., 2017).

Four focus groups were held in New Brunswick from February to April of 2019. The first two focus groups were held during a community event at a city public school. Information about the research project was circulated prior to the event by sponsoring organizations. Participants were recruited on-site by research team members carrying sandwich boards with recruitment text and positioned at designated locations. Focus group sessions were then held at a classroom in the school. The second set of two focus groups was held in meeting rooms connected to the EP community soup kitchen; participants for these sessions were recruited through EP's email list and word-ofmouth on site. All prospective participants were offered a US $\$ 25$ gift card for participating. Recruitment materials and messaging were provided in both English and Spanish. Persons who expressed interest in the project were invited to attend a focus group session on a first-come, first-serve basis, with a limit of 10 participants at each session. The principal moderator at each focus group session was a faculty researcher who spoke in English. A bilingual research assistant who spoke fluent English and Spanish was also present at each session to translate moderator questions and directions into Spanish, and to translate participant responses delivered in Spanish into English for the moderator.

The number of focus group sessions was based on judgments made by the researchers as to when sufficient data had been collected for project purposes. Once four focus group sessions had been 
conducted with a total of 33 participants, it was apparent that a coherent and consistent set of major themes and suggestions about VAPs was emerging. Additional sessions appeared unlikely to significantly change study conclusions (Hennink \& Kaiser, 2019).

\section{Data collection}

The semi-structured interview guide for focus group moderators was designed to facilitate discussion and gather rich and nuanced data around four issues: (1) Where participants usually purchase their food, and any positive or negative experiences at these venues (e.g., supermarkets, convenience stores, bodegas, FMs); (2) What foods/meals participants prepare with items purchased; (3) What kinds of VAPs are not currently offered at these venues, but which participants would like to be able to purchase; (4) What kinds of considerations, broadly speaking, would be important to participants considering whether to buy locally sourced VAPs at farmers markets and other venues. The third and fourth topics on the interview guide were considered especially crucial, as data would directly inform the development of new VAPs at EP's community kitchen. To provide a guided approach to inquiry, the food choice process model (FCPM), developed by the Cornell Food Choice Research Group (Cornell University, College of Human Ecology, 2021), was utilized to formulate subquestions for these topics. The Cornell Group used a "constructionist" approach for the original FCPM in order to give interviewees maximum flexibility to describe the complexities of food choices (Connors et al., 2001; Furst et al., 1996). For this study, we used what we term a "partially constructionist" approach. Specifically, our resource- and time-constrained interviewees were encouraged to speak freely and openly about their food preferences and choices. However, the FCPM and our knowledge about locally sourced VAPs were used to develop subquestions to probe for specific VAP attributes-such as taste, cost, and quality — which would be important to later stages of the project (Table 1). The goal was to systematically collect information using uniform questions while also enabling participants to provide insights into their experiences. Each focus group session lasted about an hour, after which participants received a handout describing the goals of the project and a $\$ 25$ gift card. All sessions were recorded with participants' consent.

\section{Table 1. Semi-structured Interview Guide for Focus Groups with New Brunswick Community Members}

\section{Questions and Follow-Up Questions}

1. Can you tell us where you usually buy your food (e.g., bodegas, corner stores, farmers markets)? If not mentioned, probe about whether they shop at farmers markets.

a. Can you share some positive experiences you've had at these places?

b. Can you share some negative experiences you've had at these places?

2. What foods/meals do you prepare with the items purchased at these places?

3. Are there any value-added products (such as canned, jarred, wrapped, etc.) currently not offered at these kinds of places, but that you wish were available for purchase?

a. Why would you want these value-added products to be offered?

b. Are certain products difficult to prepare yourself? Explain.

c. How much would you be willing to pay for these value-added products?

d. How often would you purchase these value-added products?

e. What foods/meals would you prepare with these value-added products?

4. What kinds of things do you think about before purchasing value-added products at these places? Probe for the following things:

a. Food quality (freshness, seasonality, nutrition, etc.)

b. Cost

c. Convenience (pre-packaged, ease of preparation, buying in bulk, etc.)

d. Taste

e. Food customs \& culture

f. Other things we haven't asked about

g. Are some of these things more important than others? Why? 


\section{Data analysis}

Focus group recordings were transcribed verbatim and readied for analysis using standard research procedures (Breakwell et al., 2006). Following a "thematic analysis" approach (Braun \& Clarke, 2006), personal food values identified in the FCPM literature and notes from focus group sessions were used first to develop an initial list of potential codes-brief tags or summaries of content. Each transcript was then reviewed independently by three trained coders (two co-investigators and a graduate student), who identified major themes, broadened and refined the codebook, and applied codes to project data. Coders met several times to compare analyses and come to consensus where discrepancies existed. A final codebook and set of coded focus group transcripts were then produced.

\section{Sensory Evaluation of VAPs}

The next phase of the study was aimed at understanding how New Brunswick-area consumers might react to healthy, locally sourced VAPs created with their preferences in mind. Based on findings from focus groups and interviews with local farmers on produce availability (Errickson et al., 2020), EP Promise Culinary School and project researchers worked together to develop recipes for new products. Several possible products were considered; recipe research, experimentation, internal taste tests, and nutrient analysis by a registered dietitian nutritionist took place from May to July 2019. From this process, five VAPs were successfully produced with produce provided by three local farms: tomato sauce, applesauce, zucchini pickles, hot pepper relish, and pickled jalapeños. Of these, tomato sauce and applesauce were made in large quantities due to greater availability of raw ingredients from farm partners, while the other VAPs were made in smaller quantities and later in the fall. Tomato sauce and applesauce were selected for the most extensive sensory evaluations, including comparison with store-bought brands. Hot pepper relish and pickled jalapeños were subjected to singlesample taste tests with smaller numbers of FM customers due to timing of production and available quantities.

\section{Setting and subject recruitment}

Sensory evaluation tests were conducted at FMs and community fairs in New Brunswick from September through November 2019. Researchers set up a private, tented booth at each site, and used a standardized script to ask FM customers and fair attendees who visited the booth if they would like to participate in a research study. Prospective participants were told that they would be tasting a series of products and then sharing their opinions on taste, smell, and other food characteristics. Screening questions ensured that participants with food allergies were excluded from the study.

\section{Data collection}

Sensory evaluation tests were designed to allow study participants to assess VAPs created by EP; in the case of tomato sauce and applesauce, we also collected data on participant reactions to equivalent brand-name products. After consenting to participate, participants were seated in the project's tented area and presented with samples of one or two products: (1) the VAP produced by EP (called "VAP" in results and tables for this study); and, in the case of tomato sauce and applesauce, (2) a brand-name version of the same kind of product (called "Brand"). Following standard sensory evaluation practices (Carpenter et al., 2000), product samples were served at a standard temperature and in equal amounts, and the tented area for the taste tests was private and quiet. For VAP and Brand comparisons, participants were told that the products were different examples of the same kind of food, but were not given details about specific differences in the origins or manufacture of the products. When appropriate, samples were served with a suitable accompaniment (e.g., tomato sauce with pasta). Water and saltine crackers were made available for participants to cleanse their palates between samplings.

Each VAP was assessed on its own; participants also directly compared the tomato sauce and applesauce VAP with a Brand sample. Participants scored each sample individually using a 7-point hedonic scale $(1=$ dislike very strongly to $7=$ like very strongly) to evaluate sensory attributes such as smell, taste, look, and mouthfeel (i.e., texture). For tomato sauce and applesauce, participants were 
also asked to complete a paired comparison test in which they indicated what sample was preferred based on attributes such as sweetness, spiciness, freshness, and overall taste. Finally, demographic and food frequency questions were asked of all participants in tests for tomato sauce and applesauce. These questions were not asked a second time for participants who, after evaluating tomato sauce and/or applesauce, also agreed to sample one of the other, late-season VAPs.

\section{Data analysis}

Mean scores for sensory characteristics were calculated for all samples. Paired sample $t$-tests were conducted to compare the mean score differences between Brand and VAP samples of tomato sauce and applesauce. Frequencies were also generated to illustrate preference attributes between VAP and Brand samples. Finally, descriptive statistics were produced for sociodemographic characteristics and food consumption frequencies. All analyses were conducted using Microsoft Excel.

\section{Results}

\section{Community Focus Groups}

Drawing on the FCPM Personal Food System as a guide, our analyses of the four focus groups detected 11 major themes. Following the approach taken in previous FCPM research (Connors et al., 2001), which characterized the most frequently discussed "food-related values" as "primary" and others as "additional," we grouped themes that emerged from the focus group data into two main tiers. The three major themes (with number of times mentioned by focus group participants in parentheses) were cost (37), quality (35), and health (22). Relatively minor themes were culture (14), food safety (11), familiarity (9), taste (8), convenience (7), variety (6), seasonality (6), and ethical values (6) like "buying green" and "buying local." Table 2 presents the major themes, definitions, and selected quotes supporting these themes. Throughout this section, participant comments originally made in Spanish have been translated into English.

Cost was the most frequent theme that emerged from the focus group sessions. Participants stressed the importance of comparing food prices between stores and product brands in a focused effort to maximize their limited budgets for groceries. Stores known for big sales and coupons were highly prized by nearly all participants. As one participant stated, "wherever the sales are" is where she would go to purchase food items. The overarching concern with cost carried over to how participants talked about VAPs like multi-ingredient sauces, marinades, or fruit spreads. VAPs, sometimes called "specialty" products by participants, typically were described as too expensive unless there were other compelling reasons for purchase, such as health benefits or a better overall quality product. As one participant put it: "The specialty products are kind of pricey though. So, there has to be a certain reason [to buy them]." Thus, when talking about VAPs, the discussion often turned to the topics of quality and health:

If they were homemade, I'd pay more-yeah, I'd pay more than I'd pay at a grocery store, if I knew they were homemade. And they were fresh.

So when you go to the store you're not looking for the healthy stuff, you're looking for what's on sale. You know what I mean. And that's sometimes an issue, you know what I mean, like, what you can afford. ...

Quality — broadly defined as the way food is grown, stored, prepared, or presented-was held up nearly as often as cost as a consideration in buying VAPs and other foods. Participants wanted to eat high-quality food themselves and serve the best they could afford to their families. The importance of quality to many participants made it imperative to find ways to identify food products that met their standards. This was not always easy; several participants noted that complicated labels and deceptive marketing made it hard to tell a quality product apart from look-alikes:

One of the things we always look for is whether the product has a listing of ingredients. Sometimes if it's just labeled, and there's no ingredient list, you're not sure what's in it or how it's made, so you don't trust buying it. 
As a relatively sure sign of quality, participants generally landed on one property above all: freshness. If something was fresh, it was likely to be of high quality. The intuitiveness of this relationship, and the relative ease with which the "freshness" rule could be applied, led participants to often mention "quality" and "fresh" in the same breath, as in: "I feel it's more fresh, and ... it's like the quality, you can see the difference." In response to a facilitator's question about important characteristics other than price, one participant said, "the sight [of the product]: if it's fresh, if it's quality."

Table 2. Summary of Themes from Focus Groups ( $N=4$ focus groups, with 33 participants)

\begin{tabular}{|c|c|c|}
\hline $\begin{array}{l}\text { Major Theme } \\
\text { (frequency) }\end{array}$ & Definition & Selected Quotes \\
\hline $\begin{array}{l}\text { Cost } \\
(37)\end{array}$ & $\begin{array}{l}\text { Monetary considerations related to } \\
\text { food choice, including the cost of food }\end{array}$ & $\begin{array}{l}\text { "You gotta explain to me why I should pay this price for this. Cuz, } \\
\text { if ShopRite got canned corn for ... ten for two dollars, and you } \\
\text { got pickled corn for } 75 \text { cents a jar ... I'm probably going to } \\
\text { ShopRite." }\end{array}$ \\
\hline $\begin{array}{l}\text { Quality } \\
\text { (35) }\end{array}$ & $\begin{array}{l}\text { Considerations related to how food is } \\
\text { grown, stored, prepared, or presented }\end{array}$ & $\begin{array}{l}\text { "One of the things we always look for is whether the product has } \\
\text { a listing of ingredients. Sometimes if it's just labeled, and } \\
\text { there's no ingredient list, you're not sure what's in it or how it's } \\
\text { made, so you don't trust buying it." }\end{array}$ \\
\hline $\begin{array}{l}\text { Health } \\
(22)\end{array}$ & $\begin{array}{l}\text { Considerations related to physical well- } \\
\text { being, both short-term (e.g., allergic } \\
\text { reactions, digestion) and long-term } \\
\text { (e.g., weight control, illness } \\
\text { management) }\end{array}$ & $\begin{array}{l}\text { "And I try to buy more healthy and change my mind about food } \\
\text { to change my kids' mind. So I give them more healthy things } \\
\text { every day, because I think with the example, you teach them." }\end{array}$ \\
\hline $\begin{array}{l}\text { Culture } \\
\text { (14) }\end{array}$ & $\begin{array}{l}\text { Considerations related to ethnic/ } \\
\text { national identity or religious beliefs }\end{array}$ & $\begin{array}{l}\text { "Hera main point is that she would like to see, um, see more of } \\
\text { the farmers markets getting involved and bringing more of the } \\
\text { cultural products that we need." }\end{array}$ \\
\hline $\begin{array}{l}\text { Food Safety } \\
\text { (11) }\end{array}$ & $\begin{array}{l}\text { Perceived safety of the product and } \\
\text { ingredients used in preparation }\end{array}$ & $\begin{array}{l}\text { “... if you use it today, is it gonna be good tomorrow? Or, next } \\
\text { week? Can you store it? What's the storage? You know, how } \\
\text { long will it keep in that same?” }\end{array}$ \\
\hline $\begin{array}{l}\text { Familiarity } \\
\text { (9) }\end{array}$ & $\begin{array}{l}\text { Brand recognition with a place, } \\
\text { product, or person }\end{array}$ & $\begin{array}{l}\text { "When it comes to canned goods, for frozen goods, I look for } \\
\text { brand names ... I grew up seeing them commercials ... Regard- } \\
\text { less of price, I just look for the name brand." }\end{array}$ \\
\hline $\begin{array}{l}\text { Taste } \\
\text { (8) }\end{array}$ & $\begin{array}{l}\text { Considerations related to the sensory } \\
\text { perceptions of eating and drinking }\end{array}$ & $\begin{array}{l}\text { "... I want to eat healthy, but I also want it to have flavor, so } \\
\text { that's a way to make the food taste good but it's still good for } \\
\text { you." }\end{array}$ \\
\hline $\begin{array}{l}\text { Convenience } \\
\text { (7) }\end{array}$ & $\begin{array}{l}\text { Considerations related to the time and } \\
\text { effort that individuals employ in } \\
\text { constructing food choices, including } \\
\text { time spent on acquiring, preparing, } \\
\text { eating, and cleaning up after food }\end{array}$ & $\begin{array}{l}\text { "So, she }{ }^{a} \text { would prefer to buy vegetables um, frozen than } \\
\text { canned. If they are frozen, she would get them, because they } \\
\text { are fresher and they require less time to prepare." }\end{array}$ \\
\hline $\begin{array}{l}\text { Variety } \\
\text { (6) }\end{array}$ & $\begin{array}{l}\text { Considerations related to the } \\
\text { availability and accessibility of a } \\
\text { variety of products that fit people's } \\
\text { needs }\end{array}$ & $\begin{array}{l}\text { "Yeah, when you go to the farmers market and basically what's } \\
\text { growing in New Jersey, so there's not a lot of the variety that } \\
\text { you know, the Latino community can get at the farmers } \\
\text { market." }\end{array}$ \\
\hline $\begin{array}{l}\text { Seasonality } \\
\text { (6) }\end{array}$ & $\begin{array}{l}\text { The availability of foods during certain } \\
\text { times of the year }\end{array}$ & $\begin{array}{l}\text { "Summertime she }{ }^{a} \text { would like to buy fresh, and wintertime she } \\
\text { understands she can only find it frozen." }\end{array}$ \\
\hline $\begin{array}{l}\text { Ethical Value } \\
\text { (6) }\end{array}$ & $\begin{array}{l}\text { Stated preferences for supporting } \\
\text { small, local businesses and/or buying } \\
\text { "green" products }\end{array}$ & $\begin{array}{l}\text { "I noticed that in the past bunch of years a lot of people like to } \\
\text { support local businesses and farms and stuff like that." } \\
\text { "... and, as they say, reduce the blueprint, or the food-whatever } \\
\text { it's called. The carbon print." }\end{array}$ \\
\hline
\end{tabular}

a Translation for a Spanish-speaking focus group participant. 
Asked why she liked to shop at a particular store, another participant said, "I find that [food there] is really fresh. And that's what I want."

Health, although not as frequently mentioned as cost and quality, was also an important theme during focus group sessions. In general, participants expected healthy foods to cost more, but they believed the extra expense was worth it. As one participant stated, "it's to the conscience to the people ... to buy healthy. And healthy means a little bit more expensive than what we're used to paying." Another was more blunt: "Either you pay the price to eat healthy, or you get sick, and you go to the doctor and pay that price." As with quality, participants held up certain easily identifiable properties of food as evidence of its connection to health. First, and mapping precisely onto quality, participants equated a food's healthiness with its freshness. "When you think of freshness you think, more nutritious," said one participant; another, talking about how to use fresh fruit, remarked that, "because it—and it's good, it's healthy, [so] you make agua fresca ... and you give fresh drinks to your family instead of giving some sodas." Second, food was viewed as healthy to the extent that it had not been adulterated with added ingredients, especially sodium and artificial preservatives, in order to remain safe and flavorful. Indeed, participants took the presence of preservatives in food personallynot just as a threat to one's own health, but as an offense to people in their communities:

I hate preservatives. And I hate, like, you know what I mean, the fact that people aren't as aware of how much like additives go in there. Like a lot that we eat that's really not good for you. Causes a lot of cancers and a lot of sicknesses and disease, you know what I mean. And that's a major issue among, you know, certain communities, you know.

I want to eat healthy, but I also want it to have flavor ... without all the processed stuff with a whole bunch of sodium that is killing people.

As discussed in detail above, the main goal of this project was to understand consumer food values as they might relate to VAPs produced with farm-fresh, locally sourced ingredients. Research team chefs and nutritionists found it largely encouraging that focus group participants attached high importance to food quality and health. But there were also indications that consumers' emphasis on food freshness, as an emblem of quality and health, might present a challenge to applied project goals. Specifically, many participants drew on concerns about quality and health to express negative views of canned and pre-prepared foods, which could be transposed even to locally made VAPs. Speaking about people in her social circle, one participant said, "They think that canned or jarred food is processed. When they think of quality they assume it's fresh, and by thinking like, nutrients, they think 'fresh." Another volunteered that, "I don't like canned or frozen, I try to use fresh most of the time." One participant recalled a specific dish as an example of why she did not like to use VAPs: "I prefer to use the fresh. Like, fresh asparagus and fresh tomatoes when I do my salmon. I'll use a can if I have to but if I have-if I can get the fresh I'll prefer that." Some participants even expressed surprise that certain foods could be bought pre-made at all: "You know, I never knew pickled could be in a jar ... I thought it should be natural. You know, like, you can cut it."

Focus groups provided additional information that shaped how project staff created new VAPs for the New Brunswick community. What we coded as "culture" - conceptualized as "considerations related to ethnic/national identity or religious beliefs" - was the fourth-most common theme that emerged from participant comments. As noted earlier, a plurality of New Brunswick residents identify as Hispanic or Latino, including many immigrants or relatives of immigrants from Mexico, the Dominican Republic, Puerto Rico, and Central American countries (Sandoval, n.d.). Participants in focus groups reported that many of their favorite foods were not currently available at nearby FMs, including mole, dried or preserved hot peppers, Mexican sweet breads, and salsa verde. Lamenting the absence of culturally important foods, one participant summed up several minutes of group conversation about what was missing at FMs: "Me, personally, I'm from the Dominican Republicwhen I come back [from a visit home] I would like 
to bring all the stuff we have there." Many participants made a point of actually sourcing pantry staples from their country-of-origin, like the participant who proclaimed that "my oregano comes from the D.R. [Dominican Republic]—my [family member] brings it to me every year." Moreover, the taste of store-bought foods central to Mexican, Caribbean, and Central American cultures, even when available, was seen as lacking in assertiveness, flavor, and heat. One participant described cooks in her Mexican-American family:

So when they buy the mole, they add more chili, oregano, pepper, onions, garlic, and um, chicken broth, to make it more-especially the chili-to make it more spicy. Because most of the time it's like not spicy enough for them. And the chicken is to give it more flavor.

Frequent testimonials to the effect of "there's not a lot of variety that, you know, the Latino community can get at the farmers market" made clear the importance of considering the cultural identities and culturally informed preferences of customers when developing new VAPs for specific local markets.

Food safety, environmental factors, and a preference for the familiar also influenced food purchasing decisions. Indeed, participants often conflated the issue of food contamination due to poor handling or spoilage with "contamination" due to agricultural chemicals and preservatives used in the production process. This overall negative disposition to added chemicals in food, no matter their origin, comes through in the following representative comments from two participants:

As far as like, with the handling or pesticides being on your food or whatever before you get it, all you have to do is take baking soda and water and do a soap bath before you eat it ... kills all pesticides, germs, whatever. You good.

I agree with, like, the sanitation. And also I just wanna know that it's, like, not a lot of chemicals are added into the products.

As indicated by earlier comments about health, participants largely expressed a preference for foods made without added synthetic preservatives, as the health risks of added chemicals were seen to outweigh any benefits in shelf stability. Few participants characterized themselves as adventurous eaters or interested in trying new and unfamiliar foods. However, some expressed greater willingness to try new foods, including VAPs, if they could be sure of where the product was coming from. Asked if a locally sourced VAP could ever be as appealing as the "Uncle Ben's rice" he noted by name, one participant said, "I would have to know the farm ... and the origin, the country of origin."

Themes that appeared relatively infrequently during focus groups included convenience, product variety, seasonality, and ethical values. Participants cited lack of food variety and seasonal limitations as barriers to making FMs a more central part of their shopping routines. Knowing that many FMs are only open from April to November, participants shopped at FMs for fresh fruits and vegetables during this time, but the lack of other products at FMs could make it hard to justify a separate trip for those with limited transportation. Views about "ethical consumption" surfaced only a handful of times during focus group sessions, and sometimes indirectly, as when one participant observed, "I noticed that in the past bunch of years a lot of people like to support local businesses and farms and stuff like that." Some participants, however, voiced a personal interest in using food dollars to effect social change, including through buying locally sourced VAPs: "So, I think it's good to buy local. Good to know if it's the local farm we know around, and then you know it's okay."

\section{Sensory Evaluation of VAPs}

Focus group findings guided the development of pilot batches of tomato sauce, applesauce, hot pepper relish, and pickled jalapeños VAPs to be field tested within urban FM settings. Nutrient analysis for tomato sauce and applesauce- - the products made in the largest quantities - indicated that these EP-made VAPs were healthier in terms of total calories, added sugars, and amount of sodium. VAP tomato sauce had half the calories, one-quarter the sodium, and two grams fewer total sugars compared to the Brand product (Ragu Traditional 
tomato sauce). VAP applesauce had less than onethird the total calories and less than half the total sugars, compared to the Brand product (Motts sweetened applesauce). These nutritional results were taken to align with health attributes that consumers identified as desirable during focus groups.

Among the VAPs that focus group participants specifically said were missing at New Brunswick FMs, hot pepper relish and pickled jalapeñosinspired by traditional escabeche and chiles en vinagre in Mexican cuisine (Jaramillo-Flores et al., 2010; Ko, 2020) — were the best fit with the surplus produce that was available from farm partners. Habanero peppers were the principal ingredient in the relish; the jalapeños were pickled whole with carrots, garlic, onion, and spices, and served chopped at the sensory evaluations.

\section{Sample characteristics}

Twenty-four participants completed a sensory evaluation test for tomato sauce and 25 subjects completed a test for applesauce. Hot pepper relish and pickled jalapeños each had eight subjects complete a test; as noted earlier, demographic information was not collected for these late-season VAPs, because subjects had already completed a questionnaire for tomato sauce and/or applesauce. Most participants were residents of New Brunswick or a neighboring town (tomato sauce, $87 \%$; applesauce, $65 \%$ ), and most were also frequent customers at the events where tests were conducted. Participants in all tests were majority female (tomato sauce, $62.5 \%$; applesauce, $73.9 \%$ ) and in their late 20 s to early 40 s (mean age 38.8 for tomato sauce participants; 31.6 for applesauce participants). Samples for both tests were diverse, with substantial numbers of participants identifying as Hispanic (tomato sauce, 41.7\%; applesauce, 36\%), Black and African American (tomato sauce, $27.3 \%$; applesauce, $12.0 \%$ ), and White (tomato sauce, $36.4 \%$; applesauce, $45.5 \%$ ). Among tomato sauce participants, $23.8 \%$ consumed tomato sauce more than once a week, and 33\% between once a month and once a week. Among applesauce participants, $60.9 \%$ did not consume applesauce at all, and $21.7 \%$ consumed applesauce less than once a month.

\section{Tomato sauce}

Relatively high hedonic scale mean scores for all eight attributes indicated that participants were generally satisfied with both the VAP and Brand tomato sauce. However, paired samples $t$-tests indicated significant $(p<0.05)$ differences between products on several attributes. The Brand tomato sauce was ranked significantly higher on overall taste $(6.13 \pm 1.15 \mathrm{SD}$ vs. $5.13 \pm 1.73 \mathrm{SD})$, sweetness (5.75 $\pm 1.42 \mathrm{SD}$ vs. $4.71 \pm 1.83 \mathrm{SD})$, saltiness (5.78 $1.28 \mathrm{SD}$ vs. $5.04 \pm 1.57 \mathrm{SD})$, and thickness $(6.33 \pm 1.20 \mathrm{SD}$ vs $5.21 \pm 1.64 \mathrm{SD})$ compared to the VAP (Table 3a). Results from preference and appearance tests showed comparable differences (Table 3b). About two-thirds of participants found the Brand tomato sauce to be better tasting (66.7\%), better smelling $(65.2 \%)$ and better looking $(65.2 \%)$. Most participants $(70.8 \%)$ also preferred to purchase the Brand sample over VAP (29.2\%).

\section{Applesauce}

Paired $t$-tests revealed that the VAP and Brand applesauces were broadly comparable across all attributes, except for mouthfeel, where the VAP sauce was rated significantly higher $(6.17 \pm 1.05 \mathrm{SD}$ vs. 5.08 $1.98 \mathrm{SD}$ ) (Table 4a). In side-by-side comparisons, most participants chose the VAP as the better smelling, better looking, and overall better tasting sample, while they preferred the Brand for freshness, sweetness, and thickness (Table 4b). Overall, $54.2 \%$ of participants said they would rather purchase the VAP than Brand applesauce.

Table 3a. Sensory Evaluation Results for Brand vs. VAP Tomato Sauce Samples

\begin{tabular}{lccc}
\hline & \multicolumn{3}{c}{ Tomato Sauce $(\mathrm{N}=24)$} \\
\cline { 2 - 4 } & Brand $^{\mathrm{a}}$ & VAP & Paired $t$-test \\
\hline Characteristic & Mean \pm SD & Mean \pm SD & p-value \\
\hline Overall taste & $6.13 \pm 1.15$ & $5.13 \pm 1.73$ & 0.020 \\
Appearance & $6.29 \pm 1.12$ & $5.75 \pm 1.48$ & 0.183 \\
Sweetness & $5.75 \pm 1.42$ & $4.71 \pm 1.83$ & 0.031 \\
Smell & $5.88 \pm 1.26$ & $5.88 \pm 1.15$ & 1.000 \\
Saltiness & $5.78 \pm 1.28$ & $5.04 \pm 1.57$ & 0.044 \\
Thickness & $6.33 \pm 1.20$ & $5.21 \pm 1.64$ & 0.013 \\
Mouthfeel & $6.00 \pm 1.50$ & $5.38 \pm 1.44$ & 0.182 \\
Color & $6.38 \pm 0.88$ & $6.29 \pm 0.95$ & 0.732 \\
\hline
\end{tabular}

a Brand product was Ragu Traditional. 
Table 3b. Preference and Appearance Tests Between Brand and VAP Tomato Sauce Samples

\begin{tabular}{lcr}
\hline & \multicolumn{2}{c}{ Tomato Sauce $(\mathbf{N}=\mathbf{2 4})$} \\
\cline { 2 - 3 } & \multicolumn{1}{c}{ Brand $^{\mathrm{a}}$} & \multicolumn{1}{c}{ VAP } \\
\hline Characteristic & $\mathbf{N}(\%)$ & $8(33.3)$ \\
\hline Overall tastes better & $16(66.7)$ & $14(58.3)$ \\
Spicier & $10(41.7)$ & $7(29.2)$ \\
Sweeter & $17(70.8)$ & $11(45.8)$ \\
Fresher & $13(54.2)$ & $8(34.8)$ \\
Smells better $(n=23)$ & $15(65.2)$ & $8(34.8)$ \\
Looks better $(n=23)$ & $15(65.2)$ & $7(33.3)$ \\
Saltier $(n=21)$ & $14(66.7)$ & $12(50.0)$ \\
Thicker & $12(50.0)$ & $7(29.2)$ \\
Prefer to purchase & $17(70.8)$ & \\
\hline
\end{tabular}

a Brand product was Ragu Traditional.

Table 4a. Sensory Evaluations Results for Brand vs. VAP Applesauce Samples

\begin{tabular}{lccc}
\hline & & \multicolumn{2}{c}{ Applesauce $(\boldsymbol{N}=\mathbf{2 5})$} \\
\hline Characteristic & Brand $^{\mathrm{a}}$ & VAP & Paired $t$-test \\
\hline Overall taste & $5.29 \pm 1.92$ & $6.02 \pm 1.14$ & 0.089 \\
Appearance & $5.64 \pm 1.35$ & $6.12 \pm 1.05$ & 0.149 \\
Sweetness & $5.56 \pm 1.61$ & $5.76 \pm 1.39$ & 0.760 \\
Smell & $5.88 \pm 0.85$ & $6.24 \pm 0.88$ & 0.053 \\
Thickness & $5.28 \pm 1.88$ & $5.92 \pm 1.08$ & 0.151 \\
Mouthfeel & $5.08 \pm 1.98$ & $6.17 \pm 1.05$ & 0.030 \\
Sourness & $4.88 \pm 2.01$ & $5.40 \pm 1.41$ & 0.306 \\
Color & $6.00 \pm 1.02$ & $5.96 \pm 1.31$ & 1.000 \\
\hline
\end{tabular}

a Brand product was Motts (sweetened).

Table 4b. Preference and Appearance Tests Between Brand and VAP Applesauce Samples

\begin{tabular}{lcc}
\hline & \multicolumn{2}{c}{ Applesauce $(\mathbf{N = 2 5 )}$} \\
\hline Brand & $\mathrm{N}(\%)$ & $\mathrm{N}(\%)$ \\
\hline Ovaracteristic & $11(45.8)$ & $13(54.2)$ \\
Sweeter $(n=24)$ & $14(58.3)$ & $10(41.7)$ \\
Fresher $(n=23)$ & $12(52.2)$ & $11(47.8)$ \\
Smells better $(n=21)$ & $7(33.3)$ & $14(66.7)$ \\
Looks better $(n=21)$ & $10(47.6)$ & $11(52.4)$ \\
Thicker $(n=22)$ & $12(54.5)$ & $10(45.5)$ \\
Prefer to purchase $(n=24)$ & $11(45.8)$ & $13(54.2)$ \\
\hline
\end{tabular}

a Brand product was Motts (sweetened).
Additional VAPs

The overall taste mean score for hot pepper relish $(5.63 \pm 1.30 \mathrm{SD})$ was higher than that for VAP tomato sauce but lower than that for VAP applesauce (Table 5). The overall taste mean score for pickled jalapeños $(4.50 \pm 1.60 \mathrm{SD})$ was lower than for all other VAPs (Table 6). The best category for the jalapeños was the spiciness category (5.75 $\pm 1.83 \mathrm{SD})$, while the hot pepper relish scored at least five in six out of eight categories, including overall taste.

\section{Discussion}

For this project, a mixed-methods study design informed the development of programs to produce locally sourced VAPs for urban, direct-toconsumer markets serving food-insecure consumers. Few, if any, studies have investigated the specific attributes of locally produced, smallbatch VAPs that would appeal to consumers whose current access to these products is limited.

As elaborated below, findings from this project have implications for future academic research and for concrete initiatives to produce VAPs with farm-fresh ingredients at not-for-profit food aid organizations in urban areas.

The emergence of cost as a key determinant of potential product purchases suggests that price will need to remain at the forefront of VAP programs such as that piloted for this study (Lucan et al., 2015). Finding the right price point for locally sourced VAPs requires balancing the need for revenue for farmers and food manufacturers with the imperative to maintain affordable community access to the VAPs produced. Along these lines, the acceptance of Supplemental Nutrition Assistance Program (SNAP) benefits at FMs has been shown to encourage shoppers in urban areas to attend FMs (Cotter et al., 2017), especially when paired with incentive programs such as "Double Bucks" that reward SNAP use at FMs (Charles, 2014). As most VAPs (e.g., sauces, jams, marinades) would be considered 
qualifying purchases under SNAP regulations, SNAP acceptance at FMs may provide a mechanism for alleviating urban consumers' concerns about cost as a barrier to VAP consumption. Several focus group participants also noted that buying food sourced from nearby farms could help the local economy - a perception supported in the literature (Jablonski et al., 2018). Marketing locally sourced VAPs in a manner that consistently highlights benefits to the local economy-including for farmers, food producers, and culinary workerscould increase customers' tolerance for marginally higher prices.

Thematic analysis of focus group data indicated that New Brunswick consumers would potentially be willing to pay more for FM products, including locally sourced VAPs, perceived as high quality or healthy. Quality, though deemed a main consideration in the study that first introduced the concept of a "personal food system" (Furst et al., 1996), was not a "major" value for low- tomoderate-income adults in subsequent research (Connors et al., 2001). In our study, quality again emerged as a central preoccupation for focus group participants. Moreover, in the wider academic literature on "local food," the opportunity to buy high quality, healthy food at reasonable prices is often seen as an advantage of direct-to-consumer venues like FMs (Connell et al., 2008; Freedman et al., 2016), especially when such venues are made more accessible through SNAP and similar programs. Thus, it might be expected that VAPs at FMs would benefit from their association with produce sourced from nearby farms.

However, the use of freshness by focus group participants as a key criterion for determining food quality and healthiness raises a different possibility. Specifically, even VAPs produced with fruits and vegetables from local farms may be susceptible to being viewed as not necessarily healthy, and even of questionable quality, because they are no longer in a raw, unprocessed state. Indeed, significant skepticism about the quality and healthiness of VAPs in general was an unexpected persistent theme of focus group conversations. To the extent that this finding accurately reflects sentiments among the wider population, makers of locally sourced VAPs cannot necessarily count on the
Table 5. Sensory Evaluations Results for Hot Pepper Relish

\begin{tabular}{lc}
\hline & Hot Pepper Relish VAP $(\mathbf{N = 8})$ \\
\hline Characteristic & Mean \pm SD \\
\hline Overall taste & $5.63 \pm 1.30$ \\
Appearance & $5.38 \pm 1.41$ \\
Sweetness & $5.38 \pm 1.19$ \\
Spiciness & $5.38 \pm 1.77$ \\
Smell & $5.13 \pm 1.64$ \\
Saltiness & $4.75 \pm 1.28$ \\
Mouthfeel & $5.00 \pm 2.20$ \\
Sourness & $4.63 \pm 1.77$ \\
\hline
\end{tabular}

Table 6. Sensory Evaluations Results for Pickled Jalapeños

\begin{tabular}{lc}
\hline & Pickled Jalapenos VAP $(N=8)$ \\
\hline Characteristic & Mean \pm SD \\
\hline Overall taste & $4.50 \pm 1.60$ \\
Appearance & $5.38 \pm 1.60$ \\
Sweetness & $4.43 \pm 0.53$ \\
Spiciness & $5.75 \pm 1.83$ \\
Smell & $4.86 \pm 1.21$ \\
Saltiness & $3.86 \pm 1.07$ \\
Mouthfeel & $4.75 \pm 1.49$ \\
Sourness & $4.25 \pm 0.71$ \\
\hline
\end{tabular}

freshness penumbra of FM produce- the way that customers instinctively associate freshness with FMs - carrying over to products in cans or jars.

In the context of the underlying goal of this project to produce usable information for farmers and small-scale food producers, this finding clearly calls for VAP recipes, production practices, and marketing that could assuage concerns about freshness and quality among consumers in places like New Brunswick. Consumers in food insecure areas are often all too conscious of eating too few fruits and vegetables and too much processed food (Inglis et al., 2009; Valera et al., 2009; Zenk et al., 2011). When New Brunswick residents visit FMs, they are looking for food that is fresh, because freshness is taken as a sign of quality and health. With this characteristic of the customer base in mind, producers of small-batch VAPs for FMs, including farmers and community kitchens, would 
likely do well to prioritize creating a perception of freshness for their products among urban consumers. This could be done through marketing and product design that center the healthfulness of the original ingredients, eschewing (whenever possible) preservatives and added sugars, and quantifying the nutritional content of the final product. Other strategies to reassure consumers might include displaying samples of the raw ingredients or posting appealing illustrations of the production process. When possible, FM staff or community nutrition educators might showcase VAPs in on-site demonstrations, introducing customers to new products and highlighting their roots in nearby farms. In sum, the connection of freshness, quality, and health to locally sourced VAPs cannot be taken for granted; producers must make it explicit.

Focus group results also expand the personal value system of the FCPM to include values that reflect recent FM consumer trends, including attention to ethical goals and food safety. The present study is the first to use the FCPM as a framework for exploring food choice decisions at FMs. Previous research has shown that while freshness, taste, and an enjoyable social experience are the biggest attractions of FMs for most people, a notable minority of FM shoppers attach significant importance to buying sustainable food for environmental reasons and to supporting local farmers (Carolan, 2017). While ethical and environmental considerations emerged as minor themes during focus groups, U.S. consumers as a whole are increasingly likely to consider environmental impacts when making purchasing decisions (Reganold \& Wachter, 2016). In the context of these larger social trends, factors shaping ethical consumption practices among low-income, urban consumers warrant further consideration. It is also notable that during focus groups, debate over "buying green" often went hand-in-hand with concerns over food safety. No thick line separated preferences for food that was clean, handled with care, and grown or processed without harmful chemicals, and preferences for food that was better for the environment because it was grown without pesticides. Future marketing of locally sourced VAPs might take advantage of this multidimensional attitude toward the "safety" of food, by encouraging consumers to think of their own health and the health of the broader environment as benefiting from common food system practices.

Sensory analyses offered an important groundtruthing process as follow-up to the focus group sessions, allowing for the evaluation of actual-as opposed to hypothetical-VAPs by New Brunswick-area residents. It was hypothesized that consumers would find the healthier versions of VAPs to be just as palatable as comparable brand products. Contrary to expectations, participants showed a more favorable opinion of the Brand tomato sauce compared to the EP-made tomato sauce: more than two-thirds of participants chose the Brand tomato sauce as the better tasting, sweeter, saltier, and better-looking sample, and the preferred product overall. On the other hand, slightly more than half $(54.2 \%)$ preferred the VAP applesauce to the store-bought variety. The hot pepper relish and pickled jalapeños elicited ratings that were on balance positive, but both fell short of the highest possible scores.

These results leave ample opportunity to improve urban consumer reception of VAPs. Although taste was infrequently mentioned as a food purchasing criterion during focus groups, prior FCPM research has pointed to taste as a predominant personal value in food choice (Connors et al., 2001; Furst et al., 1996). From the standpoint of concrete project goals for EP and farm partners, it was concerning that the VAP tomato sauce performed poorly versus a national brand in a blind taste test, and the pickled jalapeños did not score higher on overall taste. Clearly, recipe development must be an iterative process, and small-batch producers would benefit from being able to gather systematic, unbiased data on what consumers think of their products. At the same time, it is important to remember that, as a condition of the blind taste test, participants did not know the connection of EP products to local farms. Based on focus group findings, it stands to reason that VAPs may have a more favorable reception by urban consumers under informed conditions, where it is transparent that they are made with fresh, locally grown farm produce. As noted earlier in this section, it is likely also important to quantify the nutritional content of VAPs and highlight that information for poten- 
tial customers. Communicating these and other positive attributes to consumers, and affixing to locally sourced VAPs a price consistent with-or less than-brand products, may provide an important boost to VAPs in direct-to-consumer marketplaces like FMs.

Increasing urban consumer familiarity with the differential flavors and textures of small-batch VAPs in comparison to store brands might also improve VAP reception. Early exposure to certain foods from a young age can have a significant impact on food acceptance. Prior work has examined how visual familiarity (the awareness of foods within one's environment), taste familiarity (knowledge and experience of the taste of foods), and contextual familiarity (knowledge of how foods should be presented) begin at childhood and may determine long-term dietary development in adulthood (Aldridge et al., 2009). Indeed, as people age they tend to gravitate toward foods they have already been exposed to, as those foods give them a sense of comfort and familiarity (Aldridge et al., 2009; Locher et al., 2005).

Our finding that participants preferred the Brand tomato sauce over the healthier VAP version developed by project staff may be partially explained by lack of familiarity with, or even exposure to, healthier food products. Consumers who are unfamiliar with small-batch VAPs reminiscent of home-cooked "from scratch" meals may not perceive the VAPs as favorably as they do the store brands. The Brand tomato sauce was higher in both sugar and sodium, compared to the VAP tomato sauce. In addition, the Brand tomato sauce had a smoother appearance than the VAP tomato sauce, in which more of the tomato skins were visible. Hence, sensory evaluation participants may have preferred the Brand tomato sauce due to its familiar consistency and salty/sweet taste.

The Brand applesauce also had higher amounts of total sugar, compared to the VAP applesauce. However, more than half of participants did not regularly consume applesauce, so they may not have been influenced by past exposure to this product. In terms of appearance, both the Brand applesauce and the VAP applesauce looked very similar. Participants may have slightly favored the VAP applesauce due to the newness of the food and the generally comparable appearance of both versions.

The relatively inexpensive market research that we undertook for this study may be of interest to producers of small-batch VAPs, as well as academic investigators. With future applications in mind, it seems useful to draw attention to several limitations to our methods and to suggest ways in which these limitations could be addressed. Perhaps most important, it was evident from focus groups that many New Brunswick consumers would be eager to see new, locally sourced VAPs that fill a gap in culturally appropriate and relevant food at FMs. Participants at several focus groups mentioned pickled peppers and chiles en vinegre, suggestions which inspired the hot pepper relish and pickled jalapeños that we created with produce from farm partners. In the course of making these and other suggestions, focus group participants occasionally volunteered their country-of-origin or other aspects of their cultural identity. We did not, however, intentionally collect detailed data on what food cultures people might have identified with, or on other aspects of participants' identities that likely helped to shape their food preferences, such as country-of-origin or length of residence in the U.S. In large part, our decision not to ask these questions was based in concerns about privacy and participant recruitment. Yet, as we have stressed throughout this paper, New Brunswick is a highly diverse city, home to large numbers of people who identify with Mexican, Dominican, Puerto Rican, and other Hispanic or Latino communities. Foods that are traditional in one of these communities, like Mexican escabeche and pickled vegetables (Jaramillo-Flores et al., 2010), are not necessarily traditional or even familiar to others. With the importance of cultural diversity and its relationship to food preferences in mind, future researchers might find it useful to collect more detailed data on what VAP products would be considered culturally relevant and appropriate for the particular groups represented in specific communities and local markets.

Other limitations to our study concern how recruitment for the sensory evaluations might have shaped results. Sensory evaluations were conducted with a convenience sample of current FM custom- 
ers; this sample might not have been representative of consumers who do not currently shop at FMs, but would consider doing so in the future. Due to participants being recruited on the day of the sensory evaluations, foods or drinks that participants had consumed prior to the sensory evaluations may have impacted their taste buds and influenced their opinions. Additionally, the tomato sauce samples were presented with an accompaniment of pasta. Although tomato sauce and pasta are commonly eaten together in some cultures, in others tomato sauce is used as a base ingredient for other dishes. As such, this combination of foods may have influenced responses.

Lastly, all empirical data for this study was collected in the context of a relatively small, USDA-funded pilot project. Results suggest that significant opportunity, as well as real challenges, exist for farmers and start-up food businesses who want to earn revenue by supplying VAPs to FMs and other direct-to-consumer food venues. But additional research must be conducted, with larger sample sizes and in a wider range of areas, in order to give interested parties full confidence in the substantive, business-related conclusions of this study.

Future work on this project would likely include fine-tuning recipes for existing VAPs and adding new products to EP's portfolio. For instance, tomato skins in the EP-made VAP could be completely blended to have an appearance and texture like the generic brand product, which might better align with consumer expectations. Since most participants did not regularly consume applesauce, it would fall within the EP community service mission to work on VAPs that are more regularly consumed by New Brunswick residents. Given that applesauce may be a product of continued interest both to farmers (who are likely to have surplus fruit) and EP chefs (who now have experience producing this product), another option might be to consider an alternative market, such as a farm-to-school partnership focused on VAPs with the New Brunswick school district.

In addition, nutrition education lessons that specifically feature the healthy VAPs could be presented to FM customers at the point of purchase to help them understand the importance and health benefits of consuming low-sodium and low-sugar foods. In 2015, for example, New York's SNAPEd program conducted nutrition education interventions at 18 New York City FMs, leading to an increase in fruit and vegetable purchases (Dannefer et al., 2015). Hence, increasing consumer awareness and knowledge of the adverse health effects of high sodium/sugar foods may encourage them to try, and eventually even prefer, the healthier VAPs. Similarly, incorporating other aspects of VAPs indicated as desirable by consumers-such as quality, health, and cost-into nutrition education lessons could increase consumers' willingness to try locally sourced VAPs at FMs. Future research projects could treat these intriguing possibilities as hypotheses to be tested through field experiments at FMs, perhaps conducted in collaboration with cooperative extension or public health organizations.

\section{Conclusion}

VAP partnerships that use community-based, mixed-methods market research to bring together small farmers, food aid organizations, local food producers, and food-insecure consumers, have the potential to yield many rewards. For this study, consumer focus groups provided the opportunity for New Brunswick residents to voice personal food values that would be relevant to VAP purchasing decisions. Evaluating this qualitative data and identifying major themes informed VAP recipe development, marketing projection exercises, and sensory analyses. First-round sensory evaluations of new VAPs clearly demonstrated the challenges inherent in making healthy, locally sourced products that would satisfy the preferences of everyday consumers.

Nevertheless, this pilot project was considered a success by its directors. Focus group data was translated into product development insights, and the resulting products were competitive with, if not necessarily preferred to, store brand products. Particularly as the U.S. slowly recovers from the COVID-19 pandemic, FMs seem likely to face strong economic headwinds, even as consumer faith in the reliability of global supply chains has been shaken. The results of this study may be of use for farmers, kitchen operators, and food 
security NGOs in places like New Brunswick, where locally sourced VAPs would constitute a valuable addition to the local food landscape.

\section{Acknowledgments}

We would like to thank the New Brunswick community members who participated in this study.

\section{References}

Aldridge, V., Dovey, T. M., \& Halford, J. C. G. (2009). The role of familiarity in dietary development. Developmental Review, 29(1), 32-44. https://doi.org/10.1016/j.dr.2008.11.001

Ball, L., McCauley, A., Paul, T., Gruber, K., Haldeman, L., \& Dharod, J. (2018). Evaluating the implementation of a farmers' market targeting WIC FMNP participants. Health Promotion Practice, 19(6), 946-956. https://doi.org/10.1177/1524839917743965

Beckie, M. A., Kennedy, E. H., \& Wittman, H. (2012). Scaling up alternative food networks: Farmers' markets and the role of clustering in western Canada. Agriculture and Human Values, 29(3), 333-345. https://doi.org/10.1007/s10460-012-9359-9

Berning, J. P. (2012). Access to local agriculture and weight outcomes. Agricultural and Resource Economics Review, 41(1), 5771. https://doi.org/10.1017/S1068280500004184

Berry, J. (2019). Marketing value added products. Penn State Extension. https://extension.psu.edu/marketing-value-added-products

Bimbo, F., Bonanno, A., Nardone, G., \& Viscecchia, R. (2015). The hidden benefits of short food supply chains: Farmers' markets density and body mass index in Italy. International Food and Agribusiness Management Review, 18(1), 1-16. https://www.ifama.org/resources/Documents/v18i1/Bimbo-Bonanno-Nardone.pdf

Bloom, J. D., \& Hinrichs, C. C. (2017). The long reach of lean retailing: Firm embeddedness and Wal-Mart's implementation of local produce sourcing in the US. Environment and Planning A: Economy and Space, 49(1), $168-185$. https://doi.org/10.1177/0308518X16663207

Born, H. (2001). Keys to success in value-added agriculture. Southern Sustainable Agriculture Working Group and National Sustainable Agriculture Information Service (ATTRA). https://attra.ncat.org/product/keys-to-success-in-value-added-agriculture/

Born, H., \& Bachman, J. (2006). Adding value to farm products: An overview. National Sustainable Agriculture Information Service (ATTRA). https://attra.ncat.org/product/adding-value-to-farm-products-an-overview/

Braun, V., \& Clarke, V. (2006). Using thematic analysis in psychology. Qualitative Research in Psychology, 3(2), 77-101. https://doi.org/10.1191/1478088706qp063oa

Breakwell, G., Hammond, S. M., Fife-Schaw, C., \& Smith, J. A. (Eds.). (2006). Research methods in psychology (3rd edition). Sage.

Briggs, S., Fisher, A., Lott, M., Miller, S., \& Tessman, N. (2010). Real food, real choice: Connecting SNAP recipients with farmers markets. Farmers Market Coalition and Community Food Security Coalition. https:// farmersmarketcoalition.org/resource/real-food-real-choice-connecting-snap-recipients-with-farmersmarkets/

Brzozowski, R. (2019). Considerations for adding value to agricultural products in Maine (Bulletin \#1062). University of Maine Cooperative Extension. https://extension.umaine.edu/publications/1062e/

Carolan, M. (2017). More-than-active food citizens: A longitudinal and comparative study of alternative and conventional eaters. Rural Sociology, 82(2), 197-225. https://doi.org/10.1111/ruso.12120

Carpenter, R. P., Lyon, D. H., \& Hasdell, T. A. (Eds.) (2000). Guidelines for sensory analysis in food product development and quality control (2nd ed.). Springer. https://doi.org/10.1007/978-1-4615-4447-0

Charles, D. (2014, November 10). How 'double bucks' for food stamps conquered Capitol Hill [Radio episode]. National Public Radio's The Salt. https://www.npr.org/sections/thesalt/2014/11/10/361803607/how-double-bucks-for-food-stamps-conqueredcapitol-hill 
Clark, J. K., Jablonski, B. B. R., Inwood, S., Irish, A., \& Freedgood, J. (2020). A contemporary concept of the value(s)added food and agriculture sector and rural development. Community Development, 52(2), 186-204. https://doi.org/10.1080/15575330.2020.1854804

Collins, L. A. (2020). The effect of farmers' market access on residential property values. Applied Geography, 123, Article 102272. https://doi.org/10.1016/j.apgeog.2020.102272

Connell, D. J., Smithers, J., \& Joseph, A. (2008). Farmers' markets and the 'good food' value chain: A preliminary study. Local Environment, 13(3), 169-185. https://doi.org/10.1080/13549830701669096

Connors, M., Bisogni, C. A., Sobal, J., \& Devine, C. M. (2001). Managing values in personal food systems. Appetite, 36(3), 189-200. https://doi.org/10.1006/appe.2001.0400

Cornell University, College of Human Ecology. (2021). Food choice research group. Cornell University, College of Human Ecology. https://www.human.cornell.edu/dns/research/profiles/groups/foodchoice

Cotter, E. W., Teixeira, C., Bontrager, A., Horton, K., \& Soriano, D. (2017). Low-income adults’ perceptions of farmers' markets and community-supported agriculture programmes. Public Health Nutrition, 20(8), 1452-1460. https://doi.org/10.1017/S1368980017000088

Dannefer, R., Abrami, A., Rapoport, R., Sriphanlop, P., Sacks, R., \& Johns, M. (2015). A mixed-methods evaluation of a SNAP-Ed farmers' market-based nutrition education program. Journal of Nutrition Education and Behavior, 47(6), P516P525 E1. https://doi.org/10.1016/i.jneb.2015.08.021

Dansero, E., \& Puttilli, M. (2014). Multiple territorialities of alternative food networks: Six cases from Piedmont, Italy. Local Environment, 19(6), 626-643. https://doi.org/10.1080/13549839.2013.836163

Darnton, J. (2012, February 20). Farmers markets act as gathering space and local economic engine. Michigan State University Extension. https://www.canr.msu.edu/news/farmers markets act as gathering space and local economic engine

Downs, J. (2016, January 19). Winter farmers markets fuel local food demand. The Courier-Journal. https://www.courierjournal.com/story/life/food/2016/01/19/winter-farmers-markets-fuel-local-food-demand/78378868/

Dunne, J. B., Chambers, K. J., Giombolini, K. J., \& Schlegel, S. A. (2011). What does 'local' mean in the grocery store? Multiplicity in food retailers' perspectives on sourcing and marketing local foods. Renewable Agriculture and Food Systems, 26(1), 46-59. https://doi.org/10.1017/S1742170510000402

Errickson, L. B., Schoolman, E. D., Quick, V., Capece, A., Bastian, G. E., Chang, G., Davis, S., Flatt, J., Jimenez, M., Jimenez, M., \& Sie, A. (2020). P3 community opportunity in New Jersey: The role of food choice, farm viability, and local economy in a sustainable food future. Journal of Nutrition Education and Behavior, 52(7, Suppl.), S16-S17. https://doi.org/10.1016/j.jneb.2020.04.048

Evans, A. E., Banks, K., Jennings, R., Nehme, E., Nemec, C., Sharma, S., Hussaini, A., \& Yaroch, A. (2015). Increasing access to healthful foods: A qualitative study with residents of low-income communities. International Journal of Behavioral Nutrition and Physical Activity, 12(Suppl. 1), Article S5. https://doi.org/10.1186/1479-5868-12-S1-S5

Evans, A. E., Jennings, R., Smiley, A. W., Medina, J. L., Sharma, S. V., Rutledge, R., Stigler, M. H., \& Hoelscher, D. M. (2012). Introduction of farm stands in low-income communities increases fruit and vegetable [sic] among community residents. Health \& Place, 18(5), 1137-1143. https://doi.org/10.1016/j.healthplace.2012.04.007

Farmer, J. R., Chancellor, C., Gooding, A., Shubowitz, D., \& Bryant, A. (2011). A tale of four farmers markets: Recreation and leisure as a catalyst for sustainability. Journal of Park and Recreation Administration, 29(3), Article 3. https://js.sagamorepub.com/jpra/article/view/2252

Farmers Market Coalition. (2016). What is a farmers market? Farmers Market Coalition. https://farmersmarketcoalition.org/education/qanda/

Freedman, D. A., Vaudrin, N., Schneider, C., Trapl, E., Ohri-Vachaspati, P., Taggart, M., Ariel, C., Walsh, C., \& Flocke, S. (2016). Systematic review of factors influencing farmers' market use overall and among low-income populations. Journal of the Academy of Nutrition and Dietetics, 116(7), P1136-P1155. https://doi.org/10.1016/i.jand.2016.02.010

Furst, T., Connors, M., Bisogni, C. A., Sobal, J., \& Falk, L. W. (1996). Food choice: A conceptual model of the process. Appetite, 26(3), 247-266. https://doi.org/10.1006/appe.1996.0019 
Gerbasi, G. T. (2006). Athens farmers' market: Evolving dynamics and hidden benefits to a southeast Ohio rural community. Focus on Geography, 49(2), 1-6. https://doi.org/10.1111/j.1949-8535.2006.tb00160.x

Gillespie, G., Hilchey, D., Hinrichs, C. C., \& Feenstra, G. (2007). Farmers' markets as keystones in rebuilding local and regional food systems. In C. C. Hinrichs \& T. A. Lyson (Eds.), Remaking the North American food system: Strategies for sustainability (pp. 65-83). University of Nebraska Press.

Giurge, L. M., Whillans, A. V., \& West, C. (2020). Why time poverty matters for individuals, organisations and nations. Nature Human Behaviour, 4(10), 993-1003. https://doi.org/10.1038/s41562-020-0920-z

Govindasamy, R., Italia, J., Zurbriggen, M., \& Hossain, F. (2002). Predicting consumer willingness-to-purchase valueadded products at direct agricultural markets. Journal of Food Products Marketing, 8(1), 1-15. https://doi.org/10.1300/J038v08n01 01

Grin, B., Gayle, T. L., Saravia, D. C., \& Sanders, L. M. (2013). Use of farmers markets by mothers of WIC recipients, Miami-Dade county, Florida, 2011. Preventing Chronic Disease, 10(6), E95. https://doi.org/10.5888/pcd10.120178

Helmer, J. (2019, March 17). Why are so many farmers markets failing? Because the market is saturated. The Salt. NPR. https://www.npr.org/sections/thesalt/2019/03/17/700715793/why-are-so-many-farmers-markets-failing-becausethe-market-is-saturated

Hennink, M. M., \& Kaiser, B. N. (2019). Saturation in qualitative research. In P. Atkinson, S. Delamont, A. Cernat, J. W. Sakshaug, \& R. A. Williams (Eds.), SAGE research methods foundations. SAGE Publications. https://methods.sagepub.com/foundations/saturation-in-qualitative-research

Hinrichs, C. C., Gillespie, G. W., \& Feenstra, G. W. (2004). Social learning and innovation at retail farmers' markets. Rural Sociology, 69(1), 31-58. https://doi.org/10.1526/003601104322919892

Inglis, V., Ball, K., \& Crawford, D. (2009). Does modifying the household food budget predict changes in the healthfulness of purchasing choices among low- and high-income women? Appetite, 52(2), 273-279. https://doi.org/10.1016/j.appet.2008.10.005

Jablonski, B. B. R., McFadden, D. T., Bauman, A., \& Shideler, D. (2018, April 26). Do local food markets support profitable farms and ranches? Union of Concerned Scientists, Science Network Voices. https://blog.ucsusa.org/science-blogger/do-local-food-markets-support-profitable-farms-and-ranches

Jaramillo-Flores, M. E., Dorantes-Alvarez, L., García-Barrientos, R., \& Welti-Chanes, J. (2010). Mexican pickled jalapeño pepper. In Y. H. Hui (Ed.), Handbook of fruit and vegetable flavors (pp. 947-962). John Wiley. https://doi.org/10.1002/9780470622834.ch49

Jefrydin, N., Nor, N. M., \& Talib, R. A. (2019). Adolescents' use of the nutrition information panel for food choice: A content validation of focus group discussions. Current Research in Nutrition and Food Science Journal, 7(1), 75-84. http://dx.doi.org/10.12944/CRNFSJ.7.1.08

Johnson, A. J. (2013). 'It's more than a shopping trip': Leisure and consumption in a farmers' market. Annals of Leisure Research, 16(4), 315-331. https://doi.org/10.1080/11745398.2013.846226

Kagawa-Singer, M., Adler, S. R., Mouton, C. P., Ory, M., \& Underwood, L. G. (2009). Use of focus groups in multi-site, multi-ethnic research projects for women's health: A study of women across the nation. Ethnicity \& Disease, 19(3), 352-358. https://www.ethndis.org/

Kevern, J., \& Webb, C. (2001). Focus groups as a tool for critical social research in nurse education. Nurse Education Today, 21(4), 323-333. https://doi.org/10.1054/nedt.2001.0563

Ko, G. (2020, August 11). Make your own pickled jalapeños for tacos and so much more. The Los Angeles Times. https://www.latimes.com/food/story/2020-08-11/make-your-own-pickled-jalapenos-for-tacos-and-so-much-more

Koning, A., Borie-Holtz, D., Rogers, K., \& Young, W. (2017). New Brunswick 2016 community survey: Final report. Rutgers University, Eagleton Center for Public Interest Polling. https://eagletonpoll.rutgers.edu/wp-content/uploads/2020/04/ECPIP-NBT-2016-FINAL-REPORT-MAY2017.pdf

LeDoux, T. F., \& Vojnovic, I. (2013). Going outside the neighborhood: The shopping patterns and adaptations of disadvantaged consumers living in the lower eastside neighborhoods of Detroit, Michigan. Health \& Place, 19, 1-14. https://doi.org/10.1016/j.healthplace.2012.09.010 
Listokin, D., Berkhout, D., \& Hughes, J. W. (2016). New Brunswick, New Jersey: The decline and revitalization of urban America. Rutgers University Press. https://doi.org/10.36019/9780813575582

Locher, J. L., Yoels, W. C., Maurer, D., \& Ells, J. van. (2005). Comfort foods: An exploratory journey into the social and emotional significance of food. Food and Foodways, 13(4), 273-297. https://doi.org/10.1080/07409710500334509

Lu, R., \& Dudensing, R. (2015). What do we mean by value-added agriculture? Choices, 30(4). https://www.choicesmagazine.org/choices-magazine/submitted-articles/what-do-we-mean-by-value-addedagriculture

Lucan, S. C., Maroko, A. R., Sanon, O., Frias, R., \& Schechter, C. B. (2015). Urban farmers' markets: Accessibility, offerings, and produce variety, quality, and price compared to nearby stores. Appetite, 90, 23-30. https://doi.org/10.1016/j.appet.2015.02.034

McGill, N. (2015). Farmers markets bring healthy choices to low-income shoppers: USDA program benefits SNAP users. The Nation's Health, 45(1), 1-16. https://www.thenationshealth.org/content/45/1/1.2

McKee, E. (2021). Where do "localphiles" shop? A mixed-methods case study of food-buying habits. Journal of Agriculture, Food Systems, and Community Development, 10(2), 339-358. https://doi.org/10.5304/jafscd.2021.102.023

McManus, K. D. (2020, January 9). What are ultra-processed foods and are they bad for our health? Harvard Health Publishing, Harvard Health Blog. https://www.health.harvard.edu/blog/what-are-ultra-processed-foods-and-arethey-bad-for-our-health-2020010918605

Neri, D., Martinez-Steele, E., Monteiro, C. A., \& Levy, R. B. (2019). Consumption of ultra-processed foods and its association with added sugar content in the diets of US children, NHANES 2009-2014. Pediatric Obesity, 14(12), e12563. https://doi.org/10.1111/ijpo.12563

Oates, C. (2000). The use of focus groups in social science research. In D. Burton (Ed.), Research training for social scientists: A handbook for postgraduate researchers (pp. 186-194). SAGE Publications.

O'Hara, J. K., Woods, T. A., Dutton, N., \& Stavely, N. (2021). COVID-19's impact on farmers market sales in the Washington, D.C., area. Journal of Agricultural and Applied Economics, 53(1), 94-190. https://doi.org/10.1017/aae.2020.37

Olsho, L. E., Payne, G. H., Walker, D. K., Baronberg, S., Jernigan, J., \& Abrami, A. (2015). Impacts of a farmers' market incentive programme on fruit and vegetable access, purchase and consumption. Public Health Nutrition, 18 (Suppl. 15), 2712-2721. https://doi.org/10.1017/S1368980015001056

Pellegrino, S., Bost, A., McGonigle, M., Rosen, L., Peterson-Kosecki, A., Colon-Ramos, U., \& Robien, K. (2018). Fruit and vegetable intake among participants in a District of Columbia farmers' market incentive programme. Public Health Nutrition, 21(3), 601-606. https://doi.org/10.1017/S1368980017003020

Pitts, S. B. J., Wu, Q., McGuirt, J. T., Crawford, T. W., Keyserling, T. C., \& Ammerman, A. S. (2013). Associations between access to farmers' markets and supermarkets, shopping patterns, fruit and vegetable consumption and health indicators among women of reproductive age in eastern North Carolina, USA. Public Health Nutrition, 16(11), 1944-1952. https://doi.org/10.1017/S1368980013001389

Printezis, I., \& Grebitus, C. (2018). Marketing channels for local food. Ecological Economics, 152, 161-171. https://doi.org/10.1016/j.ecolecon.2018.05.021

Reganold, J. P., \& Wachter, J. M. (2016). Organic agriculture in the twenty-first century. Nature Plants, 2 , Article 15221. https://doi.org/10.1038/nplants.2015.221

Ruelas, V., Iverson, E., Kiekel, P., \& Peters, A. (2012). The role of farmers' markets in two low income, urban communities. Journal of Community Health, 37(3), 554-562. https://doi.org/10.1007/s10900-011-9479-y

Rundle, A., Neckerman, K. M., Freeman, L., Lovasi, G. S., Purciel, M., Quinn, J., Richards, C., Sircar, N., \& Weiss, C. (2009). Neighborhood food environment and walkability predict obesity in New York City. Environmental Health Perspectives, 117(3), 442-447. https://doi.org/10.1289/ehp.11590

Sandoval, L. (n.d.). Latino bistory of New Brunswick: A story map. Rutgers School of Arts and Sciences, Latino New Jersey History Project. https://arcg.is/1SnKmD 
Sayre, L. (2006). Marketing strategies for farmers and ranchers. Sustainable Agriculture Research and Education (SARE), Sustainable Agriculture Network. https://www.sare.org/resources/marketing-strategies-for-farmers-and-ranchers/

Schoolman, E. D. (2020). Local food and civic engagement: Do farmers who market local food feel more responsible for their communities? Rural Sociology, 85(3), 806-839. https://doi.org/10.1111/ruso.12326

Silkes, C. A. (2012). Farmers' markets: A case for culinary tourism. Journal of Culinary Science \& Technology, 10(4), 326-336. https://doi.org/10.1080/15428052.2012.733177

Spalding, B., Czarnecki, N., Hallman, W., \& Fitzgerald, N. (2012). Can farmers markets improve access and consumption of fruits and vegetables in vulnerable populations? Journal of the Academy of Nutrition and Dietetics, 112(9, Suppl.), A72. https://doi.org/10.1016/j.jand.2012.06.253

Sparks, G. (2012, Dec. 5). More communities warm up to winter markets (AMS No. 266-12). U.S. Department of Agriculture, Agricultural Marketing Service. https://www.ams.usda.gov/press-release/more-communities-warm-winter-markets

Thilmany, D., Jablonski, B., Tropp, D., Angelo, B., \& Low, S. (2020). Mitigating immediate harmful impacts of COVID-19 on farms and ranches selling through local and regional food markets. National Sustainable Agriculture Coalition. https://localfoodeconomics.com/wp-content/uploads/2020/03/2020 0321 EconomicImpactLocalFoodNSAC-SEH.pdf

Tiedje, K., Wieland, M. L., Meiers, S. J., Mohamed, A. A., Formea, C. M., Ridgeway, J. L., Asiedu, G. B., Boyum, G., Weis, J. A., Nigon, J. A., Patten, C. A., \& Sia, I. G. (2014). A focus group study of healthy eating knowledge, practices, and barriers among adult and adolescent immigrants and refugees in the United States. International Journal of Behavioral Nutrition and Physical Activity, 11(1), Article 63. https://doi.org/10.1186/1479-5868-11-63

Tropp, D. (2019). From anecdote to formal evaluation: Reflections from more than two decades on the local food research trail at USDA. Journal of Agriculture, Food Systems, and Community Development, 9(1), 13-30. https://doi.org/10.5304/jafscd.2019.091.044

U.S. Census Bureau. (2019a). New Brunswick, New Jersey, 2015-2019: ACS Demographic and Housing Estimates. U.S. Census Bureau, American Community Survey 5-year estimates. https://data.census.gov/cedsci/table?q=new $\% 20$ brunswick, $\% 20$ nj\&tid=ACSDP5Y2019.DP05\&hidePreview =false

U.S. Census Bureau. (2019b). New Brunswick, New Jersey, 2015-2019: Selected characteristics of the native and foreign-born populations. U.S. Census Bureau, American Community Survey 5-year estimates. https://data.census.gov/cedsci/table?q=new\%20brunswick, \%20nj\&tid=ACSST5Y2019.S0501\&hidePreview=false

U.S. Census Bureau. (2019c). New Jersey. U.S. Census Bureau, QuickFacts. https://www.census.gov/quickfacts/NJ

U.S. Department of Agriculture, National Agricultural Statistics Service [USDA NASS]. (2016a). Direct farm Sales of Food: Results from the 2015 Local Food Marketing Practices Survey (ACH No. 12-35). U.S. Department of Agriculture, National Agricultural Statistics Service. https://www.nass.usda.gov/Publications/Highlights/2016/LocalFoodsMarketingPractices Highlights.pdf

USDA NASS. (2016b). Executive briefing: 2015 Local Food Marketing Practices Survey. U.S. Department of Agriculture, National Agricultural Statistics Service. https://www.nass.usda.gov/Publications/AgCensus/2012/Online Resources/Local Food/pdf/LocalFoodsBriefi ngPresentation FINAL.pdf

Valera, P., Gallin, J., Schuk, D., \& Davis, N. (2009). 'Trying to eat healthy': A photovoice study about women's access to healthy food in New York City. Affilia, 24(3), 300-314. https://doi.org/10.1177/0886109909337378

Wittman, H., Beckie, M., \& Hergesheimer, C. (2012). Linking local food systems and the social economy? Future roles for farmers' markets in Alberta and British Columbia. Rural Sociology, 77(1), 36-61. https://doi.org/10.1111/j.1549-0831.2011.00068.x

Zenk, S. N., Odoms-Young, A. M., Dallas, C., Hardy, E., Watkins, A., Hoskins-Wroten, J., \& Holland, L. (2011). You have to hunt for the fruits, the vegetables': Environmental barriers and adaptive strategies to acquire food in a lowincome African American neighborhood. Health Education \& Behavior, 38(3), 282-292. https://doi.org/10.1177/1090198110372877

Zepeda, L., Chang, H.-S., \& Leviten-Reid, C. (2006). Organic food demand: A focus group study involving Caucasian and African-American shoppers. Agriculture and Human Values, 23(3), Article 385. https://doi.org/10.1007/s10460-006-9001-9 